\title{
LA CONSTITUCIONALIZACIÓN DE LA PROHIBICIÓN DE ABUSO DE LOS DERECHOS CONTRACTUALES: APROXIMACIÓN HISTÓRICA A SUS RAÍCES MORALES
}

Joaquín Acosta Rodríguez Mónica Lucía Fernández Muñoz

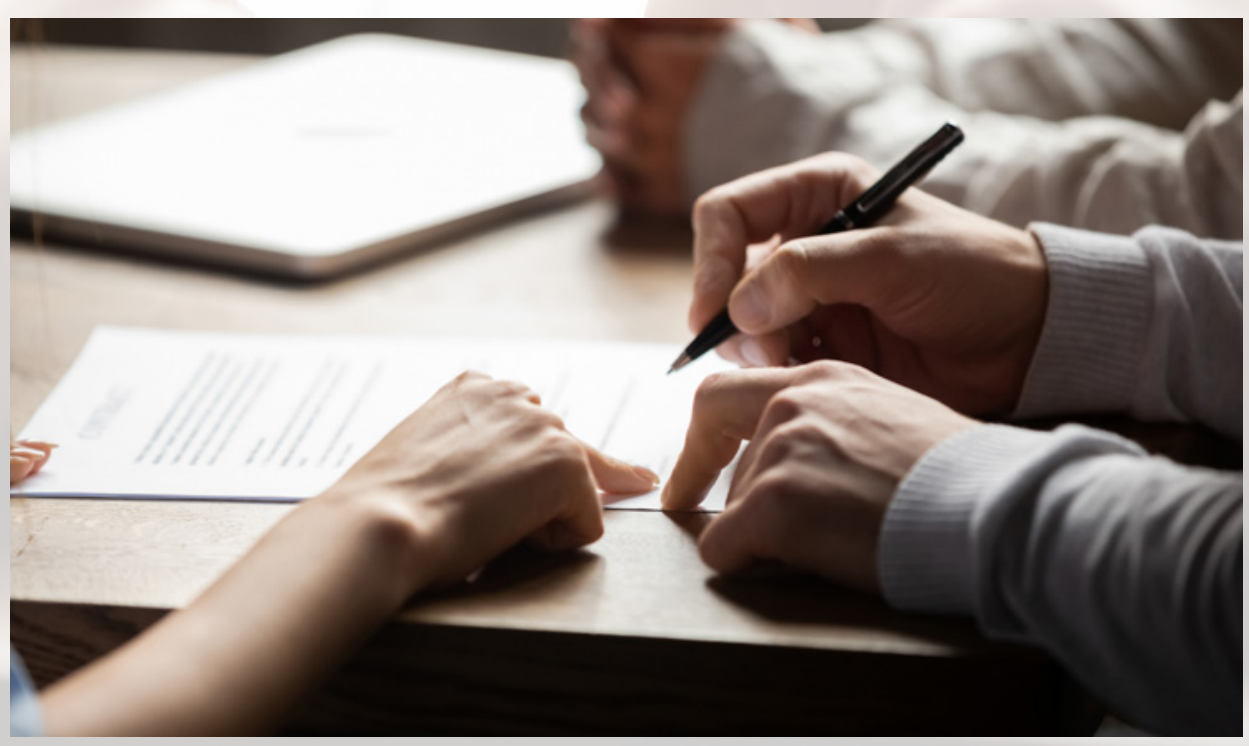





\title{
LA CONSTITUCIONALIZACIÓN DE LA PROHIBICIÓN DE ABUSO DE LOS DERECHOS CONTRACTUALES: APROXIMACIÓN HISTÓRICA A SUS RAÍCES MORALES*
}

\author{
JoAquín Acosta Rodríguez \\ Mónica Lucía Fernández Muñoz \\ Universidad La Gran Colombia \\ Politécnico Grancolombiano
}

\section{Resumen}

En Colombia, la prohibición del abuso del derecho ha alcanzado rango constitucional. Así, se aumenta el deber en el operador jurídico de darle efecto útil a tal disposición, incluso en el ámbito contractual. Sin embargo, la noción de abuso se observa altamente problemática y de esta manera ha sido vista como una amenaza a la seguridad jurídica. Su empleo se verifica en la jurisprudencia iusprivatista, creciente en la mayor parte de las ramas del derecho. La especialidad contractualista no constituye excepción a esta tendencia. En consecuencia, este imperativo exige investigar la concreción del abuso en los vínculos contractuales, a fin de resaltar, inventariar y analizar todas las manifestaciones de abuso en el ámbito contractual. Para tales efectos a partir de investigaciones doctrinales precedentes en derecho francés de contratos, se efectuará una aproximación histórica de la teoría del abuso del derecho, que irá desde los precedentes del derecho romano hasta los albores de la era moderna, desde la comprensión del abuso contractual como conducta merecedora de sanción.

Palabras clave: abuso del derecho, abuso de prerrogativa contractual, derecho comparado de contratos, historia del derecho de contratos.

\footnotetext{
El presente trabajo es fruto de la colaboración de los autores, pertenecientes a los grupos de investigación Teoría del derecho, la justicia y la política, de la Universidad La Gran Colombia, y Derecho, sociedad e industrias creativas, del Politécnico Grancolombiano, respectivamente.
} 
Los autores: Joaquín Acosta Rodríguez, doctor en Derecho de los negocios. Docente investigador de la Facultad de Derecho de la Universidad La Gran Colombia. ORCID: 0000-0002-6849-1577. Correo electrónico: joaquinacosta2001@yahoo.fr

Mónica Lucia Fernández Muñoz, doctora en Personas y tutelas jurídicas. Docente investigadora del Politécnico Grancolombiano. ORCID: 0000-0002-7885-8600. Correo electrónico: mfernand@ poligran.edu.co

Recibido: 29 de septiembre de 2021; evaluado: 12 de enero de 2022; aceptado: 14 de febrero de 2022. 


\title{
THE CONSTITUTIONALIZATION OF THE PROHIBITION OF CONTRACT RIGHTS ABUSE: A HISTORICAL APPROACH TO THE MORAL ROOTS OF THIS REGIME
}

\author{
JoAQuín ACOSTA RodríGUEz \\ Mónica Lucía Fernández Muñoz \\ Universidad La Gran Colombia \\ Politécnico Grancolombiano
}

\begin{abstract}
In Colombia, the prohibition of abuse of rights has reached constitutional status. Thus, the legal operator's duty to give useful effect to such provision has increased, in the contractual sphere as well. However, the notion of abuse is highly problematic, and it has been seen as a threat to legal security. Its use can be verified through growing amounts of jurisprudence in every area of the law, with contract law being no exception. Consequently, this imperative requires investigating each specific contractual abuse with the aim to highlight, inventory, and analyze all manifestations of abuse. For this purpose, based on previous doctrinal research in French contract law, the paper offers a historical approach to the theory of abuse of law, from the precedents of Roman law to the dawn of the modern Era, from understanding contractual abuse as conduct worthy of sanction to establishing the guiltiness of the contracting parties.
\end{abstract}

Keywords: abuse of law, abuse of contractual right, comparative contract law, history of contract law. 
The authors: Joaquín Acosta Rodríguez, PhD in Business Law. Research professor at the Law School of the Universidad La Gran Colombia. ORCID: 0000-0002-6849-1577. E-mail: joaquinacosta2001@ yahoo.fr

Mónica Lucia Fernández Muñoz, PhD in Legal Persons and Guardianships. Research professor at the Politécnico Grancolombiano. ORCID: 0000-0002-7885-8600. E-mail: mfernand@poligran.edu.co

Received: September 29, 2021; evaluated: January 12, 2022; accepted: February 14, 2022. 


\title{
A CONSTITUCIONALIZAÇÃO DA PROIBIÇÃO DE ABUSO DOS DIREITOS CONTRATUAIS: ABORDAGEM HISTÓRICA DE SUAS RAÍZES MORAIS
}

\author{
Joaquín Acosta Rodríguez \\ Mónica Lucía Fernández Muñoz \\ Universidad la Gran Colombia \\ Politécnico Grancolombiano
}

\section{Resumo}

$\mathrm{Na}$ Colômbia, a proibição do abuso do direito atingiu um nível constitucional. Assim, aumenta-se o dever no operador jurídico de dar efeito útil a tal disposição, inclusive no âmbito contratual. Contudo, a noção de abuso é observada altamente problemática e, dessa maneira, vem sendo vista como uma ameaça à segurança jurídica. Seu emprego é verificado na jurisprudência jusprivatista, crescente na maior parte dos ramos do direito. A especialidade contratualista não constitui exceção a essa tendência. Em consequência, esse imperativo exige investigar a concretização do abuso nos vínculos contratuais, a fim de ressaltar, inventariar e analisar todas as manifestações de abuso no âmbito contratual. Para isso, com base em pesquisas doutrinais precedentes em direito francês de contratos, é feita uma abordagem histórica da teoria do abuso do direito, que vai desde os precedentes do direito romano até o início da era moderna, a partir da compreensão do abuso contratual como conduta merecedora de sanção.

Palavras-chave: abuso do direito, abuso de prerrogativa contratual, direito comparado de contratos, história do direito de contratos. 
Os autores: Joaquín Acosta Rodríguez, doutor em Direito dos Negócios. Docente pesquisador da Faculdade de Direito da Universidad La Gran Colombia. ORCID: 0000-0002-6849-1577. Correio eletrônico: joaquinacosta2001@yahoo.fr

Mónica Lucia Fernández Muñoz, doutora em Pessoas e Tutelas Jurídicas. Docente pesquisadora do Politécnico Grancolombiano. ORCID: 0000-0002-7885-8600. Correio eletrônico: mfernand@ poligran.edu.co

Recebido: 29 de setembro de 2021; avaliado: 12 de janeiro de 2022; aceito: 14 de fevereiro de 2022. 


\section{Introducción}

La Constitución colombiana exige "respetar los derechos ajenos y no abusar de los propios". ${ }^{1}$ Por su parte, el abuso se define como "acción y efecto de hacer uso excesivo, injusto o indebido de algo o alguien". ${ }^{2}$ Para el profesor Cornu, en derecho se trata del "uso excesivo de una prerrogativa jurídica". ${ }^{3}$ La prohibición de abuso es uno de los medios supremos que permiten sancionar al demandante deshonesto justo cuando piensa que va a triunfar. ${ }^{4}$ Se trata, una vez más, de garantizar la equidad y, así, la justicia. ${ }^{5} \mathrm{Tal}$ como acontece con la buena fe, la noción de abuso es naturalmente problemática ${ }^{6} \mathrm{y}$, por ende, parece poco compatible con la seguridad jurídica. ${ }^{7}$ Sin embargo, la cualificación de abuso se multiplica en todos los campos: ${ }^{8}$ derecho civil, de sociedades, de la competencia, penal, fiscal y laboral.

El mismo fenómeno se aprecia en derecho de contratos. ${ }^{9}$ En consecuencia, es preciso investigar la concreción del abuso en los vínculos contractuales, con el fin de resaltar, inventariar y analizar todas las manifestaciones de abuso en el ámbito contractual. El desarrollo del abuso en el contrato es un fenómeno reciente. ${ }^{10}$ Desde luego, la noción de mala fe podría absorber la cuestión del abuso; para aumentar la confusión, la jurisprudencia emplea los dos términos sin aparente distinción. El creciente empleo de los dos términos —en Colombia, de rango constitucional—,

\footnotetext{
"La calidad de colombiano enaltece a todos los miembros de la comunidad nacional. Todos están en el deber de engrandecerla y dignificarla. El ejercicio de los derechos y libertades reconocidos en esta Constitución implica responsabilidades. Toda persona está obligada a cumplir la Constitución y las leyes. Son deberes de la persona y del ciudadano: 1) Respetar los derechos ajenos y no abusar de los propios [...]". República de Colombia, Constitución Política (Bogotá: Legis, 1991), art. 95.

2 Real Academia Española, "Abusar" en Diccionario de la lengua española, https://dle.rae.es/abusar (acceso septiembre 21, 2021)

3 Gérard Cornu, Vocabulaire juridique, 6a ed. (París: PUF, 2004), 123.

4 Georges Ripert, "Abus ou relativité des droits", Revue Critique de Legislation et de Jurisprudence 33, núm. 1 (1929): 7, https://heinonline.org/HOL/LandingPage?handle=hein.journals/rcritlgj88\& div=4\&id=\&page= (acceso septiembre 21, 2021).

5 Georges Durry, "Obs. sous, 12 oct. 1971", Revue trimestrielle de droit civil (1972): 398.

6 Pierre Godé, "Observations sous le décret n 78-464 du 24 mars 1978 portant détermination les premières clauses réputées abusives", Revue trimestrielle de droit civil (1978): 744-746.

7 Denis Mazeaud, "Le juge face aux clauses abusives" en Le juge et l'exécution du contrat, colloque IDA Aix-enProvence, ed. Institut de Droit des Affaires (Marsella: PU Aix-Marseille, 1993), 23 y 26.

8 Philippe Stoffel-Munck, L'abus dans le contrat: essai d'une théorie (París: LGDJ, 2000), 2.

9 Joaquín Emilio Acosta Rodríguez y José Manuel Gual Acosta, "La delimitación de la libertad contractual en virtud de exigencias sociales", Iusta, núm. 55 (2021): 16, DOI: https://doi.org/10.15332/25005286.6850 (acceso septiembre 21, 2021).

10 Acosta Rodríguez y Gual Acosta, "La delimitación", 5.
} 
así como su frecuente sinonimia, impone confrontarlas. ${ }^{11}$ Para tales efectos, se partirá de investigaciones doctrinales precedentes. ${ }^{12}$

Tales hallazgos, en derecho francés de contratos, anuncian una síntesis del estado del debate, que podría desembocar en una auténtica teoría ${ }^{13}$ que aclarará los elementos que la cualificación de abuso observa con los principios fundamentales del derecho de contratos. Ese enfoque permitiría superar la desconcertante diversidad abigarrada de contradicciones otorgadas a la teoría del abuso del derecho, no sólo en Colombia, ${ }^{14}$ sino en la doctrina jurídica foránea. ${ }^{15}$

\section{Metodología}

Con el método empleado en investigaciones precedentes ${ }^{16}$ daremos inicio al presente ejercicio a partir de la historia de la teoría del abuso del derecho, desde sus precedentes en el derecho romano hasta los albores de la era moderna, así como su comprensión en tanto conducta merecedora de sanción a la culpabilidad de los contratantes.

11 Los defensores de una concepción amplia de la buena fe encontrarán, en los desarrollos siguientes, aspectos y conceptos que habrían asimilado a la mala fe. En este punto, la querella será, creemos, mayoritariamente semántica. Los fenómenos que unos denominarán "mala fe" corresponderán para otros al "abuso". No obstante, iqué importa el término, en tanto la lógica del fenómeno sea decantada!

12 Stoffel-Munck, L'abus dans; Abbas Karimi, Les clauses abusives et la théorie de l'abus de droit (París: LGDJ, 2001); Pascal Ancel, "Critères et sanctions de l'abus de droit en matière contractuelle" en C D entr., núm. 6 (1998): 30; Sophie Stijns, "Abus, mais de quel(s) droit(s)? Réflexions sur l'exécution de bonne foi des contrats et l'abus de droits contractuels", Journal des Tribunaux (1990): 33; Ripert, "Abus ou relativité"; Louis Josserand, De l'esprit des droits et de leur relativité. Théorie dite de l'abus de droit (París: Dalloz, 2006). En derecho colombiano, Ernesto Rengifo García, Del abuso del derecho al abuso de la posición dominante (Bogotá: Universidad Externado de Colombia, 2004).

13 Es decir, un sistema explicativo racional. "[...] théorie, sens général: "construction spéculative de l'esprit rattachant des conséquences à des principes' dsd; adde sens $3^{\circ}$ : 'ce qui est l'objet d'une conception méthodique, systématiquement organisée". André Lalande, Vocabulaire technique et critique de la philosophie, 3a ed. (París: Presses Universitaires de France, 1993), 73.

14 Rengifo García, Del abuso, 23.

15 Milivoié Markovitch, La théorie de l'abus des droits en droit comparé (Tesis de doctorado, Universidad de Lyon, 1936), 17.

16 Joaquín Emilio Acosta Rodríguez, "Libertad, derecho y democracia: un análisis desde el paradigma del contrato (individual y social)", Estudios de Derecho 75, núm. 166 (2019): 119, DOI: https://doi.org/10.17533/ udea.esde.v75n166a06 (acceso septiembre 21, 2021). 


\section{La mirada sobre el derecho francés para mejor comprender la problemática latinoamericana}

Sin duda, el derecho francés, pionero de la codificación, ha constituido un modelo ampliamente difundido, no solo en Europa, sino en otros sistemas de obediencia romanista, como los de América Latina. ${ }^{17}$

Ahora bien, en lugar de efectuar un estudio que consistiría en una comparación estricta del derecho de contratos en los regímenes jurídicos colombiano y francés, el análisis situará el eje en el derecho francés. Este sistema será la referencia principal en materia jurídica contractual. Ello permitirá aprehender, a medida que se avance en la temática, las perspectivas abiertas para el derecho latinoamericano en referencia con el derecho francés. ${ }^{18}$ Se estima que el ámbito jurídico regional extraerá ingentes beneficios en virtud de tal enfoque.

Según los doctrinantes de nuestro país, ${ }^{19}$ el estudio del derecho de obligaciones y contratos recibe mayor riqueza cuando tiene en cuenta las fuentes de donde

17 Sobre la difusión del Code Napoléon en América Latina, Matthew Mirow, "The power of Codification in Latin America. Simón Bolívar and the Code Napoleon", Tulane Journal of International and Comparative Law 8 (2000): 83, https://ecollections.law.fiu.edu/cgi/viewcontent.cgi?referer $=\$$ httpsredir $=1$ \&article $=1120 \&$ context=faculty_publications (acceso septiembre 21, 2021).

Alejandro Guzmán Brito, La codificación civil en Iberoamérica, siglos XIX y XX (Santiago: Editorial Jurídica de Chile, 2000), 83; Estudios de historia dogmática y sistémica sobre el Código Civil chileno-colombiano (Bogotá: Diké, 2009), 22; "El código Napoleón y el Código Civil de Chile", Boletín de la Academia Nacional de Derecho y Ciencias Sociales de Córdoba. Estudios en honor de Pedro I. Frías (1994): 1361; Carlos Augusto Ramos Núñez, El código napoleónico y su recepción en América Latina (Lima: Pontificia Universidad Católica del Perú, 1997), 34; Christian Larroumet, dir. "Lavenir de la codification en France et en Amérique Latine, Actes du colloque international organisé par l'Association Andrés Bello des juristes franco-latino-américains", https://www.senat. fr/colloques/colloque_codification/colloque_codification_mono.html (acceso septiembre 21, 2021); Jorge Cortabarría, "El Code Napoleón y sus comentaristas como fuentes del Código Civil argentino", Iushistoria, núm. 1 (2005): https://p3.usal.edu.ar/index.php/iushistoria/article/view/1644/2077 (acceso septiembre 29, 2021).

18 Ciro Nolberto Güechá Medina y Jessica Tatiana Güechá Torres, "Reparación de daños por violación de la confianza y esperanzas legítimas: un análisis de los sistemas jurídicos francés y colombiano", Via Inveniendi et Iudicandi 16, núm. 2 (2021): 39, DOI: https://doi.org/10.15332/19090528.6782 (acceso septiembre 21, 2021).

19 José Alejandro Bonivento Fernández, Los principales contratos civiles y su paralelo con los mercantiles (Bogotá: Librería Ediciones del Profesional, 2019), 79; Guillermo Ospina Fernández y Eduardo Ospina Acosta, Teoría general del contrato y del negocio jurídico, 7a ed. (Bogotá: Temis, 2009), 92; Jaime Alberto Arrubla Paucar, Contratos mercantiles, Tomo III: Contratos atípicos (Bogotá: Diké, 2006), 32; Raimundo Emiliani Román, Curso razonado de las obligaciones: la obligación civil y sus fuentes voluntarias, Tomo I: Parte primera (Bogotá: Universidad Sergio Arboleda, 2001), art. 132. 
emana la organización jurídica nacional. ${ }^{20}$ "Referirse a los orígenes de ese derecho [colombiano] constituye una base de comprensión de sus orientaciones y principios. El derecho civil francés constituye una referencia ineludible para quienes pretenden profundizar la teoría jurídica colombiana". ${ }^{21}$ El derecho francés ocupará la mayor parte de este trabajo, para facilitar la comprensión del derecho colombiano ${ }^{22}$ y, en general, del latinoamericano, fuertemente influenciado por la tradición jurídica de ese país europeo.

\section{Las grandes etapas de la historia de la prohibición del abuso del derecho}

Si bien hay autores que afirman que la teoría del abuso del derecho es connatural a la tradición jurídica misma, ${ }^{23}$ ello correspondería a asimilar tal noción a otras instituciones vecinas, tales como la buena fe o la equidad. Y, como se verifica entre buena fe y buenas costumbres, un enfoque histórico permite identificar sus diferencias funcionales, a pesar de las similitudes. ${ }^{24}$

La intención de causar daño es el primer criterio de la culpabilidad en el ejercicio de un derecho contractual que será denominado abuso. ${ }^{25}$ En efecto, pareciera que

20 Fabrice Hourquebie, "L'indépendance de la justice dans les pays francophones", Les Cahiers de la Justice, núm. 2 (2012): 51.

21 Texto original: "Se référer aux origines de ce droit constitue une base de compréhension de ses orientations et de ses principes. Le droit civil français constitue une référence incontournable pour ceux qui veulent approfondir la théorie juridique colombienne". Adriana Cely, Fondements de la responsabilité civile des dirigeants des sociétés: etude comparée franco-colombienne (París: Editions universitaires europeennes, 2011), 13.

22 Rodrigo Hernán Torrejano Vargas y Henry Bocanegra Acosta, "Con el futuro que soñamos los neogranadinos: proposiciones de avance económico para una nueva realidad social (1778-1813)", Via Inveniendi et Iudicandi 16, núm. 2 (2021). DOI: https://doi.org/10.15332/19090528.6784 (acceso septiembre 21, 2021).

23 "Nous estimons que la notion de l'abus dérive de la nature même du droit; c'est pourquoi tout système de droit comportait déjà certaines règles interdisant une sorte d'abus des droits". Karimi, Les clauses abusives, 29. Georges Ripert vincula el principio "nemo auditur propriam turpitudinem allegans" y la teoría del abuso del derecho. Georges Ripert, La règle morale dans les obligations civiles (París: LGDJ, 1949), 108.

24 La buena fe fue creada en el siglo I a. C. para solucionar las dificultades derivadas de la interpretación literal de los contratos, mientras que las buenas costumbres nacieron durante el reinado de Diocleciano, en el siglo III d. C., para luchar en especial contra las estipulaciones de sucesión futura y los abusos de los terratenientes contra los "humiliores" en las ventas de los bienes inmuebles. Más adelante, en la Edad Media, la noción fue utilizada para privar de eficacia un juramento cuyo cumplimiento conducía a un obrar ilícito. En los tiempos modernos, el espíritu jansenista también refrenó la fuerza de la libertad contractual en nombre de las buenas costumbres y otorgó al juez un poder de apreciación, contrario a las ideas revolucionarias que consideraban conveniente confinar al juez a la aplicación mecánica del derecho. En tal sentido, Jean-Philippe Lévy y Andre Castaldo, Histoire du droit civil (París: Dalloz, 2002), 232.

25 Nohora Elena Pardo Posada, "Un recorrido por los derechos colectivos en la jurisprudencia argentina", Via Inveniendi et Iudicandi 9, núm. 1 (2014): 31, DOI: https://doi.org/10.15332/s1909-0528.2014.0001.02 (acceso septiembre 21, 2021). 
los especialistas concuerdan en declarar responsable al acreedor cuando obra bajo el imperio de esta acción reprochable: la intención de perjudicar genera responsabilidad cuando provoca perjuicio. ${ }^{26}$ Esta communis opinio de ninguna manera observa, si hablamos honestamente, algo de moderno o específico. La condena al ejercicio de un derecho que observe animus nocendi es una solución constante, tanto con anterioridad como con posterioridad a la codificación moderna. ${ }^{27}$ En consecuencia y para fines de demostración, se expondrá la evolución histórica de la sanción al dolo, en tanto precedente invocado en la prohibición de abuso del derecho desde la época romana.

\subsection{Represión de la malicia con anterioridad a la codificación moderna}

La represión de la malicia ha sido consagrada por el derecho romano y por l'ancien droit. ${ }^{28}$ Sin embargo, en uno y otro caso, no parece que el ejercicio concomitante de un derecho haya constituido la sustancia del problema. ${ }^{29}$ Convendrá explorar el desarrollo de esta represión de la malicia desde sus raíces antiguas y recrear la influencia que el derecho canónico y l'ancien droit han determinado respecto a tal noción.

\subsection{El aporte del derecho romano}

Los autores que sostienen que la teoría del abuso del derecho se aplicaba mucho antes de que fuera doctrinalmente expuesta remontan los primeros antecedentes en la época romana. ${ }^{30}$ Entonces, se comenzará por el análisis de la exceptio doli generalis y luego se hará una apreciación crítica.

26 Nattaly Palomares García y Jorge Calonje Londoño, "Tratados de libre comercio Colombia-Asia: cuestión preliminar y perfiles de negociación", Iusta 43, núm. 1 (2015): 17, DOI: https://doi.org/10.15332/s19000448.2015.0043.06 (acceso septiembre 21, 2021).

27 Santiago Patarroyo Rengifo y Paola Andrea Benavides Gómez, "Rupturas asignificantes: revisiones críticas en torno al derecho", Via Inveniendi et Iudicandi 9, núm. 1 (2014): 23, DOI: https://doi.org/10.15332/ s1909-0528.2014.0001.01 (acceso septiembre 21, 2021).

28 La expresión "l'ancien droit" corresponde en Francia al sistema jurídico vigente en el Ancien Régime, es decir, desde la monarquía hasta el advenimiento de la Revolución Francesa. En adelante se instauró, al menos formalmente, un "nouveau droit" (el derecho francés contemporáneo), basado en principios y dogmas jurídicos nuevos.

29 Stoffel-Munck, L'abus dans, 29.

30 Ripert, La règle morale, 108

"Au contraire, d'après nous, il ne faut pas chercher pour la règle de l'abus de droit une origine étrangère, ni un commencement précis. Si on remonte dans le passé de n'importe quel système de droit, on y trouvera une origine et le moment de l'épanouissement de la règle en question". Karimi, Les clauses abusives, 29. 


\subsubsection{La exceptio doli generalis}

En Roma existía la exceptio doli generalis, cuando menos en las obras de Gayo, quien manifestara: "si in ea re nihil dolo malo Auli Agerii factum sit neque fiat". ${ }^{31}$ De esta frase han sido deducidas dos instituciones: i) la exceptio doli praeriti o specialis, ${ }^{32}$ que procede por el hecho de obrar dolosamente en el pasado, y ii) la exceptio doli praesentis o generalis, ${ }^{33}$ que procede por el hecho de obrar dolosamente en el presente. Según los romanistas alemanes, ${ }^{34}$ esta institución conoció una ampliación considerable en derecho romano. Poco a poco se fue prescindiendo de la condición de dolo, de mala fe o de la exigencia de culpa. Una simple contravención objetiva a la bona fides o a la equidad terminó siendo suficiente. De esta manera, se incurría en dolo cada vez que la acción en justicia del demandante contravenía a la equidad. Gracias a tal concepción extendida, la exceptio doli generalis se convirtió en el medio para introducir nuevas instituciones conocidas en el derecho privado actual tales como el derecho de retención o la compensación.

Los jurisconsultos romanos han plasmado en el Digesto doctrinas que condenan a quien obra con la intención de perjudicar a otro, por el simple hecho de su intención. ${ }^{35}$ A título de ejemplo, debe resaltarse, en primer lugar, la frase de Celso a propósito de la acción en reivindicación: "[... ] neque malitiis indulgentum est". ${ }^{36}$ Así mismo, Ulpiano aprueba a Marcelo por haber considerado, a propósito del propietario que obstruye en su inmueble la corriente de agua que alimenta la del vecino, que "Sane non debet habere [de dolo actionem] si non animo vicino nocendi, sed suum agrum meliorem faciendi id fecit" ${ }^{37}$ Javoleno estima que el propietario que contamina con humo a su vecino dispone de la acción de iniuriis, si la causa de la acción de injuria se concede a aquel cuyos bienes han sido perseguidos por un falso acreedor, siempre y cuando este último supiera carecer de crédito legítimo. ${ }^{38}$ Gayo también señaló: "[...] male enim nostro iure uti non debemus aussi bien à propos des maîtres excessivement cruels envers leurs esclaves que des

\footnotetext{
31 Gayo IV, 119: "Si en este asunto Aulo Agerio no obró ni obra dolosamente".

32 Excepción de dolo especial.

33 Excepción de dolo general o presente.

34 Béatrice Jaluzot, La bonne foi dans les contrats. Étude comparative des droits français, allemand et japonais (París: Dalloz, 2001), 424.

35 Etienne Perreau, "Origines et développement de la théorie de l'abus du droit", Revue générale du droit (1913): 481.

36 Dig. VI, I, De rei vindicatione, 38.

37 No debe sufrir la acción de dolo si no obró para perjudicar a su vecino, sino para mejorar su predio. Dig. XXXIX, III, De aqua et aquae pluviae arcendae, 1 y 2; adde eod. loc., 2, 9: Paulo, quien contempla el caso en el cual el propietario obra ut vicino noceatur.

38 Inst. Just., 4, de iniuriis, 1.
} 
prodigues qui dilapident le patrimoine familial". ${ }^{39}$ En conclusión la jurisprudencia romana se negó a reconocer determinadas acciones en justicia debido a la inmoralidad del demandante, según el célebre principio "Nemo auditur propriam turpitudinem allegans", ${ }^{40}$ el cual sigue siendo aplicado por los jueces y ocupa un lugar destacado en las discusiones doctrinales. ${ }^{41}$

\subsubsection{Apreciación crítica}

Se podría encontrar en las anteriores citaciones la prueba de la voluntad del derecho romano de reprimir la intención dolosa misma, como sin duda el derecho griego antiguo lo hacía. ${ }^{42}$ Sin embargo, semejante afirmación exige las correspondientes matizaciones, ya que, como lo indica el profesor Stoffel-Munck, ${ }^{43}$ el Digesto ofrece un número comparable de ilustraciones que permiten sustentar la tesis inversa. En efecto, el mismo Gayo estima que "nullus videtur dolo facere qui suo iure utitur". ${ }^{44}$ Un poco más lejos, Paulo, quien en principio afirmó que "non omnes quod licet honestum est", ${ }^{45}$ también sentenció: "[...] nemo damnun facit, nisi qui id fecit quod facere ius non habet" ${ }^{46}$ e, incluso, converge con Gayo: "[...] non videtur vim facere, qui suo iure utitur". ${ }^{47}$

La explicación de estas aparentes contradicciones puede ser presentada de dos maneras. En primer lugar, se ha sostenido que las opiniones que afirman la impunidad de quienes ejercen su derecho son las excepciones a una regla general contraria; ${ }^{48}$

39 Inst. I, 53. No debemos hacer mal uso de nuestro derecho. En el caso de crueldad con la cual los amos ejercían su poder, Gayo precisa que la regla se impuso mediante la Constitución del emperador Antonino. Al aprobarla, afirmó el famoso male enim; luego, indicó que por la misma razón (qua ratione) se explica la interdicción de los pródigos, quienes estropean con su intemperancia el uso de su derecho a administrar sus bienes. Nadie puede alegar su propia torpeza o negligencia. Dig., XII, 5, 8.

41 Ripert, La règle morale, 104.

42 Louis Gernet, "Note sur la notion de délit privé en droit grec" en Droits de l'Antiquité et sociologie juridique: mélanges Henri Lévy-Bruhl, ed. Institut de Droit Romain. Bruhl (París: Sirey, 1959), 393 y 396.

43 Stoffel-Munck, L'abus dans, 30.

Para Karimi, tales reglas "ne changent rien. En effet, elles sont considérées comme les principes généraux qui justifient, d'ailleurs, la nécessité des règles sanctionnant l'abus de droit. S'il en était autrement et s'il n'y avait pas de règle déclarant que tout exercice de droit est protégé, aucune raison ne se manifesterait d'exclure certains exercices des droits de la protection légale". Karimi, Les clauses abusives, 30.

44 Nadie obra mal al ejercer su derecho. Dig., L, XVII, de diversis regulis iuris antiquis, 55.

45 Lo que es lícito no es necesariamente honesto. Dig., L, XVII, de diversis regulis iuris antiquis, 144.

46 Nadie obra mal si no ha hecho aquello a lo cual no tenía el derecho de hacer. Dig., L, XVII, de diversis regulis iuris antiquis, 151.

47 Nadie hace el mal si simplemente ejerce su derecho. Dig., L, XVII, de diversis regulis iuris antiquis, 155.

48 Charles Appleton, "Les exercices pratiques dans l'enseignement du droit romain et plan d'un cours sur l'abus des droits", Revue internationale de l'enseignement 78 (1924): 142 y 150, https://education.persee.fr/ doc/revin_1775-6014_1924_num_78_1_7748 (acceso septiembre 21, 2021). 
no obstante, dado que ninguna regla epistemológica impide que tal planteamiento sea invertido, este resulta poco convincente. ${ }^{49}$ Por otra parte, se pretende explicar tales contradicciones al reubicarlas en una cronología. Los comentarios rigurosos serían formulados a propósito de reglas arcaicas y estrictas, mientras aquellos que permiten la represión de la malicia corresponden a reglas más "modernas". ${ }^{50}$ Esta interpretación tiene el mérito de reconocer una evolución comprobada en el derecho romano. En efecto, este se moralizó. La institución del pretor ha permitido la corrección de los excesos del estricto ius civile..$^{51}$

El desarrollo de la moral estoica incitó a los pretores a hacer que el derecho romano fuera menos indiferente a las manifestaciones de malicia presentes en los litigios. Así mismo, la condena a la intención de perjudicar se encuentra libre de cualquier duda en los contratos bonae fidei. ${ }^{52}$

Sin embargo, no es posible deducir de esas reglas una teoría del abuso del derecho, como lo han pretendido algunos defensores modernos. En efecto, el derecho romano no es abstracto y general, elaborado sobre una arquitectura de grandes principios que inspiran las soluciones; por el contrario, es casuista y en extremo concreto, que sin duda no concibió la noción abstracta de una responsabilidad general por culpabilidad..$^{53}$

La responsabilidad se articula por el conducto de la noción de delito y el tercer capítulo de la lex Aquilia, si bien contempla una serie de casos que han sido objeto de una interpretación extensiva, no puede ser presentado como el equivalente del artículo 1382 del Code francés, modelo del artículo 2341 de nuestro Código Civil. ${ }^{54}$

49 Stoffel-Munck, L'abus dans, 30.

50 Gerardo Broggini, "Labus de droit et le principe de la bonne foi : aspects historiques et comparatifs" en Abus de droit et bonne foi, eds. Pierre Widmer y Bernard Cottier (Friburgo: Université de Fribourg, 1994), 3 y 6.

51 Papiniano escribió que el derecho pretoriano era: "Quod praetores introduxerunt adjuvendi, supplendi, vel corrigendi iuris civilis gratia". Dig., I, I, 7, I. Es decir, lo que los pretores han introducido para ayudar, complementar o corregir el derecho civil.

52 Broggini, "Labus de droit", 3 y 5; Pierre Bonassies, Le dol dans la conclusion des contrats (Lille: Faculté de Droit de l'Université de Lille, 1955), 26.

53 Henri Mazeaud, Traité théorique et pratique de la responsabilité civile délictuelle et contractuelle, Conventions de responsabilité, clause pénale, assurances de responsabilité, fonds de garantie, 6a ed. (París: Montchrestien, 1983), 22; Georges Ripert y Jean Boulanger, Traité de droit civil: d'après le traité de Planiol, Tomo II (París: LGDJ, 1957), 963.

54 Jean-Luc Gazzaniga, Introduction historique au droit des obligations (París: PUF, 1992), 193. Solo en su etapa final y gracias a los bizantinos, el derecho romano reconoció una acción cuasigeneral para los daños causados a otros. 
Por otra parte, no pareciera que el derecho romano hubiera concebido la idea técnica del derecho subjetivo, en tanto autorización individual otorgada abstractamente contra todos ${ }^{55}$ Esta noción, que supone el establecimiento de un sistema jurídico basado en la autonomía del individuo, no correspondería al espíritu romano y su edificación teórica, en realidad, correspondería a una época muy posterior. ${ }^{56}$ Resulta un tanto exagerado atribuir al genio romano la edificación de una teoría cuyos materiales no disponía y jamás predicó; parece dudoso, cuando menos, que el derecho pretoriano romano constituya "la marcha triunfal del abuso", para retomar la expresión del maestro Josserand..$^{57}$

Es mucho más probable que los romanos jamás hayan concebido tal teoría y que los impresionantes ejercicios de ingenio elaborados para demostrar lo contrario respondan, más bien, a una necesidad académica de legitimación con base en la historia que de un objetivo de verdad histórica. ${ }^{58}$ La consideración de la malicia en derecho romano solo demuestra entonces la constante condena autónoma del animus nocendi. Esta también se encuentra en l'ancien droit. ${ }^{59}$

\section{La sanción al dolo en l'ancien droit}

Que la intención de dañar desempeña un papel relevante en l'ancien droit no sorprende a los especialistas. La poderosa influencia de la religión cristiana sobre el derecho impone esta solución. ${ }^{60}$ En ocasiones, esta referencia religiosa es explícita en las obras doctrinales de la época. Se la encuentra en los juristas cristianos Ripert y Boulanger, quienes indican que la regla moral considerada producto de una moral laica es, en realidad, la que el cristianismo ha legado al mundo. ${ }^{61}$ El maestro

55 Rafael Sänger, "La garantía de la propiedad y el principio de proporcionalidad como límites de la carga tributaria en Alemania", Iusta, núm. 42 (2015); 46, https://revistas.usantotomas.edu.co/index.php/iusta/ article/download/2480/2416 (acceso septiembre 21, 2021).

56 Christophe Jamin, "Typologie des théories juridiques de l'abus de droit", Contr. conc., consom., núm. 92 (1996): 7; Michel Villey, Le droit et les droits de l'homme (París: PUF, 1990), 69; Philosophie du droit, 4a ed, Tomo I (París: Dalloz, 1986), 134.

57 Texto original: "[...] la marche triomphale de l'abus". Louis Josserand, De l'esprit, 89.

58 El profesor Jamin habla de una "fonction de légitimation" por el Derecho romano, considerado entonces como un modelo casi imposible de superar. Jamin, "Typologie des théories", 7.

59 Eduardo Rodríguez Martínez, "El pasaje del Estado y el derecho a la Postmodernidad", Via Inveniendi et Iudicandi 11, núm. 2 (2016): 26, https://doi.org/10.15332/s1909-0528.2016.0002.01 (acceso septiembre 21, 2021).

60 Sobre esta influencia, Henri Gilles, "La culpabilité dans l'ancien droit français", Annales de l'Université des sciences sociales de Toulouse, núm. XXIV (1976): 36.

61 "Sans qu'on doive d'ailleurs méconnaître ce que le christianisme doit lui-même à la philosophie grecque", es decir, sin que se deba desconocer lo que el cristianismo debe a la filosofía griega, añaden estos autores. Ripert y Boulanger, Traité de droit, 10. 
Carbonnier constató, a su turno, que la moral es la máscara con la cual la religión se cubre para hacerse aceptar por aquellos que no la estiman. ${ }^{62}$

Respecto a la cuestión del abuso del derecho propiamente, Lemée confirma el rol eminente de esos principios de nuestro derecho positivo, en el fondo tomados de la moral judeocristiana, la cual fundamenta las normas de nuestra civilización. ${ }^{63}$ Se tiene que fuentes con marcas religiosas influenciaron una primera corriente doctrinal que, cuando menos, es un germen de la teoría del abuso. ${ }^{64}$ En consecuencia, se comenzará por el análisis de l'ancienne jurisprudence ${ }^{65}$ y luego se expondrá una apreciación crítica.

\subsection{L'ancienne jurisprudence}

L'ancienne jurisprudence ilustra la influencia religiosa en un determinado número de situaciones características de lo que luego se denominó abuso del derecho ${ }^{66}$ Por ejemplo, se registra una sentencia del Parlement d'Aix, del 1 de febrero de $1577 .{ }^{67}$ Este fallo sancionó a un cardador de lana que, al cantar sin descanso en su taller, atormentaba maliciosamente los estudios de su vecino, un abogado. Demolombe, a pesar de ser hostil a la idea de responsabilidad por el ejercicio abusivo de un derecho, se abstuvo de criticar esta solución, ya que, según él, el cardador no ejercía su "derecho" a cantar, sino que, más bien, "afectaba" el canto. ${ }^{68}$ Ahora bien, tal matización resulta frágil. ${ }^{69}$ Parece que, vinculada o no al ejercicio de un derecho, la actitud del cardador fue reprochada, al tener como objetivo el mortificar al abogado, como lo resalta el Parlement. Se puede considerar que la sanción se fundamenta en la represión a la intención de perjudicar. ${ }^{70}$

La idea según la cual la malicia debe ser reprimida en sí misma, en l'ancien droit, se detecta de una manera más neta de la lectura de los jurisconsultos. Desde el siglo

\footnotetext{
Jean Carbonnier, Flexible droit (París: LGDJ, 1998), 83.

Julien Lemée, "Essaie sur la théorie de l'abus de droit, thèse dact", Paris XII, núm. 558 (1977), 400

Stoffel-Munck, L'abus dans, 24.

65 Esto es, la jurisprudencia proferida durante la vigencia de l'ancien droit.

${ }_{66}$ Carolina Blanco Alvarado, "El recordatorio a la determinación del contenido esencial de los derechos fundamentales, atendiendo el escenario de la pandemia por el covid-19 en el Estado colombiano", Novum Jus 15, núm. 1 (2021): 51, DOI: https://doi.org/10.14718/NovumJus.2021.15.1.2 (acceso septiembre 21, 2021).

67 Destacada por Boniface/Bonifacio en Recueil des arrêts de Provence, t. III, livre II, título I, chap. II.

68 Charles Demolombe, Cours de Code Napoléon, Tomo XII, 2a ed. (París: A. Durand, 1859), 650.

69 Stoffel-Munck, L'abus dans, 32.

70 Etienne Perreau, "Origines et développement de la théorie de l'abus du droit", Revue générale du droit (1913): 488.
} 
XIII, Philippe de Beaumanoir se tomó la molestia en sus Coutumes de Beauvaisis, de recomendarle al alguacil de abstenerse de aplicar estrictamente la regla de derecho cuando resultara una crueldad inútil. ${ }^{71}$ En el siglo XVI, Guy Coquille dictaminó que el propietario de un predio podía extraer pozos para escurrir el agua que interfería con el arado, aunque el vecino terminara perjudicado, siempre y cuando no se pretendiera perjudicarle, así como quien hiciera el trabajo no pudiera drenar el agua de su terreno mediante otros medios. ${ }^{72}$ Pierre de L'Hommeau indicó en el mismo sentido que a nadie le estaba permitido efectuar en su predio algo inútil, al tiempo que perjudicara a un tercero. ${ }^{73}$ Otros autores hicieron planteamientos análogos ${ }^{74}$ bastará con citar al más ilustre de todos: Domat, quien consideró que quien adelantara una nueva obra en su terreno usaría su derecho sin desconocer ley, costumbre o título de posesión que podría subyugarlo con sus vecinos no era responsable de los daños que pudieron sufrir; a no ser que tal novedad se hubiera edificado para perjudicar a otros, sin mayor utilidad para sí. En ese caso, se trataría de una malicia que la equidad no podría tolerar. ${ }^{75}$

Los ejemplos son concernientes a las relaciones de vecindad, las cuales, durante un largo período, constituyeron el típico caso en el que la mala intención hacía degenerar como culpable un acto habitualmente protegido por el derecho. ${ }^{76}$ En materia contractual, se resalta, a propósito de las cláusulas de cesión de arrendamiento o de subarrendamiento, que la negativa de autorización injustificada por parte del arrendador provocaba la exoneración de responsabilidad del arrendatario ${ }^{77}$ Pothier,

71 Horace Clarac, "Droit et pitié dans les coutumes de Beauvaisis de Philippe de Beaumanoir", 1952, citado en Stoffel-Munck, L'abus dans, 32.

72 "Coutumes du Nivernais", chap. X, art. 1, citado en Georges Appert, Note sous Trib. de Sedan, 17 déc. 1901 (Ciudad: Editorial, 1904), 217.

73 Maximes générales du droit français, art. 420, en Appert, Note sous, 217.

74 Demolombe reenvía a Bannelier sur Davot ("Des droits de voisinage", Liv. II, tit. VIII, § 2, nº 45) así como a Dunod ("Des prescriptions", part. I, chap. XII). Demolombe, Cours, 648.

Appert se refiere a las Coutumes de Paris, de Normandie, de Reims ou de Sens. Appert, note sous, 217

Etienne Perreau cita adicionalmente a Ferrière, Dareau y Fournel. Perreau, "Origines et développement", 481.

Antoine d'Espeisses.

75 Jean Domat, Les lois civiles dans leur ordre naturel, t. IV, París, 1822, livre II, titre VIII, Section III, nº 9. La cita es frecuentemente atribuida, por error, al Livre III de la primera parte Des lois civiles.

76 Se pueden establecer como una temática aparte los casos de abuso en el ejercicio de mecanismos procesales. En efecto, se trata de un problema real ampliamente analizado, como lo demuestran Les Plaideurs de Racine o, más jurídicamente, una ordonnance de Francisco I de 1539, la cual dispone que se otorguen judicialmente daños y perjuicios proporcionales la temeridad de la acción. François Laurent, Principes de droit civil français, Tomo XX (Bruselas: Bruylant-Christophe \& cie, 1876), 412.

77 Guillermo García Garzón y Mauricio Fino Serrano, "Los impuestos territoriales en Colombia y la inequidad social: ¿la voluntad de la clase dominante erigida en ley?", Iusta, núm. 41 (julio-diciembre, 2014): 70, https:// revistas.usantotomas.edu.co/index.php/iusta/article/view/2471 (acceso febrero 2, 2018). 
por su parte, citó una jurisprudencia del Châtelet d'Orléans así como del Châtelet de París y señaló que, cuando el arrendatario, obligado a restituir el inmueble, presentara al seigneur d'hôtel (arrendador) un subarrendatario oeque idoneum, es decir, que para todos los efectos le sea indiferente al seigneur d'hôtel que sea este o el arrendatario principal quien ocupara el inmueble, el único efecto de la cláusula era que el seigneur podría retomar su edificación y lograr la declaración de terminación del arrendamiento. Pero si no quería retomar el arriendo, no debía ser atendido ni se le debía permitir obstaculizar la ejecución del subarriendo. ${ }^{78}$

\subsection{Apreciación crítica}

Es menester hacer gala de extrema prudencia a la hora de extraer conclusiones de este breve repaso de l'ancien droit. Si bien resulta claro que la máxima Malitiis non est indulgendum ha sido más o menos explícitamente acogida en determinados ámbitos, un estudio histórico de conjunto sigue pendiente. ${ }^{79}$ En materia contractual, la hipótesis del ejercicio malicioso de las prerrogativas del acreedor no parece haber llamado la atención de los jurisconsultos. No obstante, cuando Domat ve en la fuerza obligatoria de las convenciones un corolario del "amour mutuel" y considera que todos los contratos son de buena fe, para nada es irrealista deducir que la malicia por él condenada en las relaciones de vecindad estaría prohibida en las relaciones entre contratantes. ${ }^{80}$ De esta manera, criticar, con autores como D’Aguesseau, los "fallos sentimentales" inspirados por la caridad ${ }^{81}$ no implica que se permita prosperar impunemente la malicia.

La ausencia de comentarios relativos a la hipótesis de un acreedor que usaría su derecho contractual por pura malicia y animus nocendi no es significativa. Este silencio se explica mejor por la rareza práctica de tales supuestos, por lo que no se exige un desarrollo particular en los tratados de la época. Tal omisión no correspondería a una posición doctrinal en la materia.

Sin embargo, es temerario deducir que un concepto específico de abuso del derecho por malicia hubiera sido concebido en l'ancien droit. Desde luego, contrario al derecho romano, los instrumentos técnicos de esa teoría están aparentemente

\footnotetext{
Robert Joseph Pothier, Traité du contrat de louage, Tomo IV (París: Debure Père, 1848), 99.

Stoffel-Munck, L'abus dans, 34.

80 Robert Joseph Pothier, Traité des obligations, selon les regles tant du for de la conscience, que du for extérieur (París: Debure l'âné, 1764), 29.

81 Pierre Bellet, "Le juge et l'équité" en Études offertes à René Rodière, ed. René Rodière (París: Dalloz, 1981), 9.
} 
reunidos. Un principio general de responsabilidad se ha establecido, cuando menos, desde el siglo XIV, el cual cristaliza la idea de un derecho subjetivo concebido como un poder cuya titularidad le es reconocida al individuo. ${ }^{82}$ No obstante, en su tesis doctoral, Stoffel-Munck considera que en esta época, el derecho subjetivo no era el alfa y omega de las relaciones entre particulares. ${ }^{83}$ Este más bien se enfocaba en proteger al individuo contra la arbitrariedad del poder público. La noción se habría construido contra el absolutismo del rey y no contra el propietario o el acreedor, quienes nunca han sido asimilados — al menos, hasta la presente fecha- a un monarca dotado de poder absoluto. ${ }^{84}$ La lectura de los tratados de la época da la impresión de que las relaciones de derecho privado fueron analizadas de manera menos dogmática. ${ }^{85}$ La búsqueda concreta de un justo equilibrio entre las partes procesales domina el razonamiento judicial más que la aplicación de soluciones deducidas a partir de una visión abstracta de la sociedad, en la cual cada individuo detentaría derechos subjetivos absolutos contra los demás. El espíritu de geometría, el espíritu de sistema, no es propio de l'ancien droit civil. Considerar que la sanción a la maldad del acreedor es improcedente en virtud del ejercicio de un derecho subjetivo y que tal situación goza de una presunción de licitud implica la formulación de un problema cuyos términos habrían parecido incongruentes a los mejores jurisconsultos de ese tiempo. Es más verosímil estimar que l'ancien droit ha considerado que la malicia constituye en sí una incorrección que exige una represión, independientemente del hecho de que se manifieste en un acto que es habitualmente justo. ${ }^{86}$

\section{Conclusión}

La represión de la intención de producir daño fue concebida mucho antes de la codificación moderna. Sin embargo, la ausencia de la noción técnica de derecho subjetivo absoluto impide asimilar por completo esta solución a la teoría moderna del abuso del derecho. Así las cosas, correspondería ver en la sanción al dolo anterior a la codificación una reacción de las autoridades contra las violaciones

\footnotetext{
82 Michel Villey, "La genèse du droit subjectif chez Guillaume d'Occam", Archives de philosophie du droit (1964): 98.

83 Stoffel-Munck, L'abus dans, 34.

84 Milton Quiroz Villalobos, "Acercamiento a las 'oposiciones paradigmáticas' entre neoconstitucionalismo y positivismo jurídico", Iusta 2, núm. 41 (2015): 77-97, DOI: https://doi.org/10.15332/s1900-0448.2014.0041.03 (acceso septiembre 21, 2021).

85 Fernanda Navas Camargo, "El Sur Global y la realidad social de América Latina: hacia la construcción de nuevos paradigmas", Novum Jus 14, núm. 2 (2020): 43. https://novumjus.ucatolica.edu.co/article/view/3689 (acceso septiembre 21, 2021).

86 Navas Camargo, "El Sur", 12.
} 
más chocantes a los principios de civilidad y honestidad. No obstante, este repaso histórico está lejos de deconstruir el interés de la teoría contemporánea del abuso del derecho. En efecto, la historia demuestra que ha sido necesario reprimir la malicia — también contractual—, así esta sea manifestada mediante un acto que habitualmente se exhibe lícito.

Es útil tomar nota de la manera como ha sido aprehendida la cuestión del ejercicio malicioso de un derecho con anterioridad a la codificación moderna. Así se contará con una herramienta conceptual que facilitará el contraste con la forma en que el problema ha sido encarado durante los últimos dos siglos. ${ }^{87}$

Por otra parte, la evolución histórica de la represión a la malicia ilustra una tendencia en el derecho privado: la de remontar los orígenes de las instituciones civilistas al ius civile. Tal ejercicio no siempre es fiel a la verdad histórica y, peor aún, ha contribuido a idealizar el derecho romano. Lejos de ser una tendencia inocente, esta tradición ha reforzado el conservadurismo innato del jurista en el derecho civil contemporáneo. Toda propuesta que se aleje de la auténtica tradición romanista tiende a ser vista con natural desconfianza, así se trate de una innovación conveniente y necesaria para la innegable necesidad de adaptar la disciplina a desafíos inéditos como la posindustrialización, la sociedad de consumo, la era electrónica o la globalización, desconocidos por el mundo clásico, cuyos valores no siempre convergen con los de nuestro tiempo.

A menudo percibido como un instrumento inmutable, heredado del derecho romano, el contrato se encuentra íntimamente ligado a las ideas filosóficas y económicas preponderantes de cada época. ${ }^{88}$ En consecuencia, la principal finalidad de su marco jurídico debería ser la adaptación de sus reglas a los valores y principios imperantes, en lugar de rendirle homenaje al genio de los jurisconsultos romanos al apegarse anacrónicamente a sus concepciones jurídicas.

\section{Referencias}

Acosta Rodríguez, Joaquín Emilio y José Manuel Gual Acosta. "La delimitación de la libertad contractual en virtud de exigencias sociales". Iusta, núm. 55 (2021): 1-27, DOI: https:// doi.org/10.15332/25005286.6850 (acceso septiembre 21, 2021).

\footnotetext{
87 Aspiramos efectuar tal ejercicio en futuras publicaciones.

88 François Terré, Philippe Simler e Yves Lequette, Droit civil: les obligations (París: Dalloz, 2011), 305.
} 
Acosta Rodríguez, Joaquín Emilio. "Libertad, derecho y democracia: un análisis desde el paradigma del contrato (individual y social)". Estudios de Derecho 75, núm. 166 (2019): 116-135, DOI: https://doi.org/10.17533/udea.esde.v75n166a06 (acceso septiembre 21, 2021).

Appert, Georges. Note sous Trib. de Sedan, 17 déc. 1901. Sedan, 1904.

Appleton, Charles. "Les exercices pratiques dans l'enseignement du droit romain et plan d'un cours sur l'abus des droits". Revue internationale de l'enseignement 78 (1924): 142-158, https://education.persee.fr/doc/revin_1775-6014_1924_num_78_1_7748 (acceso septiembre 21, 2021).

Arrubla Paucar, Jaime Alberto. Contratos mercantiles. Tomo III: Contratos atípicos. Bogotá: Diké, 2006.

Bellet, Pierre. "Le juge et l'équité" en Études offertes à René Rodière, editado por René Rodière, 9-15. París: Dalloz, 1981.

Blanco Alvarado, Carolina. "El recordatorio a la determinación del contenido esencial de los derechos fundamentales, atendiendo el escenario de la pandemia por el covid-19 en el Estado colombiano". Novum Jus 15, núm. 1 (2021): 17-40. DOI: https://doi. org/10.14718/NovumJus.2021.15.1.2 (acceso septiembre 21, 2021).

Bonassies, Pierre. Le dol dans la conclusion des contrats. Lille: Faculté de Droit de l'Université de Lille, 1955.

Bonivento Fernández, José Alejandro. Los principales contratos civiles y su paralelo con los mercantiles. Bogotá: Librería Ediciones del Profesional, 2019.

Broggini, Gerardo. "L'abus de droit et le principe de la bonne foi: aspects historiques et comparatifs" en Abus de droit et bonne foi, editado por Pierre Widmer y Bernard Cottier, 3-21. Friburgo: Université de Fribourg, 1994.

Carbonnier, Jean. Flexible droit. París: LGDJ, 1998.

Cely, Adriana. Fondements de la responsabilité civile des dirigeants des sociétés: etude comparée franco-colombienne. París: Editions Universitaires Europeennes, 2011.

Cornu, Gérard. Vocabulaire juridique. 6a ed. París: PUF, 2004.

Cortabarría, Jorge. "El Code Napoleón y sus comentaristas como fuentes del Código Civil argentino". Iushistoria Revista electrónica, núm. 1 (2005). https://p3.usal.edu.ar/index. php/iushistoria/article/view/1644/2077 (acceso septiembre 29, 2021).

Demolombe, Charles. Cours de Code Napoléon. Tomo XII. 2a ed. París: A. Durand, 1859. Durry, Georges. "Obs. sous, 12 oct. 1971". Revue Trimestrielle de droit civil (1972): 701-712. Emiliani Roman, Raimundo. Curso razonado de las obligaciones: la obligación civil y sus fuentes voluntarias. Tomo I: Parte primera. Bogotá: Universidad Sergio Arboleda, 2001.

García Garzón, Guillermo y Mauricio Fino Serrano. "Los impuestos territoriales en Colombia y la inequidad social: ¿la voluntad de la clase dominante erigida en ley?”. Iusta, núm. 
41 (julio-diciembre, 2014): 61-75, https://revistas.usantotomas.edu.co/index.php/ iusta/article/view/2471 (acceso febrero 2, 2018).

Gazzaniga, Jean-Luc. Introduction historique au droit des obligations. París: PUF, 1992.

Gernet, Louis. "Note sur la notion de délit privé en droit grec" en Droits de l'Antiquité et sociologie juridique: mélanges Henri Lévy-Bruhl, editado por Institut de Droit Romain. Bruhl, París: Sirey, 1959.

Gilles, Henri. "La culpabilité dans l'ancien droit français". Annales de l'Université des sciences sociales de Toulouse, núm. XXIV (1976): 35-44.

Godé, Pierre. "Observations sous le décret n 78-464 du 24 mars 1978 portant détermination les premières clauses réputées abusives". Revue trimestrielle de droit civil (1978): 655-672. Güechá Medina, Ciro Nolberto y Jessica Tatiana Güechá Torres. "Reparación de daños por violación de la confianza y esperanzas legítimas: un análisis de los sistemas jurídicos francés y colombiano". Via Inveniendi Et Iudicandi 16, núm. 2 (2021) : 1-41, DOI: https://doi.org/10.15332/19090528.6782 (acceso septiembre 21, 2021).

Guzmán Brito, Alejandro. "El código Napoleón y el Código Civil de Chile". Boletín de la Academia Nacional de Derecho y Ciencias Sociales de Córdoba. Estudios en honor de Pedro I. Frías 10 (1994): 1361-1376.

Guzmán Brito, Alejandro. Estudios de historia dogmática y sistémica sobre el Código Civil chileno-colombiano. Bogotá: Diké, 2009.

Guzmán Brito, Alejandro. La codificación civil en Iberoamérica, siglos XIX y XX. Santiago: Editorial Jurídica de Chile, 2000.

Hourquebie, Fabrice. "L'indépendance de la justice dans les pays francophones". Les Cahiers de la Justice, núm. 2 (2012): 41-61.

Jaluzot, Béatrice. La bonne foi dans les contrats. Étude comparative des droits français, allemand et japonais. París: Dalloz, 2001.

Jamin, Christophe. "Typologie des théories juridiques de l'abus de droit". Contrats- Concurrence-Consommation, núm. 92 (1996): 18-34.

Josserand, Louis. De l'esprit des droits et de leur relativité. Théorie dite de l'abus de droit. París: Dalloz, 2006.

Karimi, Abbas. Les clauses abusives et la théorie de l'abus de droit. París: LGDJ, 2001.

Lalande, André. Vocabulaire technique et critique de la philosophie. 3a ed. París: Presses Universitaires de France, 1993.

Larroumet, Christian. (dir.). "L’avenir de la codification en France et en Amérique Latine, Actes du colloque international organisé par l'Association Andrés Bello des juristes franco-latino-américains, 2004". https://www.senat.fr/colloques/colloque_codification/ colloque_codification_mono.html (acceso septiembre 21, 2021).

Laurent, François. Principes de droit civil français. Tomo XX. Bruselas: A. Durand \& Pedone Lauriel, 1876. 
Lemée, Julien. "Essaie sur la théorie de l'abus de droit. Thèse dact". Paris XII, núm. 558 (1977).

Lévy, Jean-Philippe y Andre Castaldo. Histoire du droit civil. París: Dalloz, 2002.

Markovitch, Milivoïé. La théorie de l'abus des droits en droit comparé. Tesis de doctorado, Universidad de Lyon, 1936.

Mazeaud, Denis. "Le juge face aux clauses abusives" en Le juge et l'exécution du contrat, colloque IDA Aix-en-Provence, editado por Institut de Droit des Affaires, 27-42. Aix en Provenza: PU Aix-Marseille, 1993.

Mazeaud, Henri. Traité théorique et pratique de la responsabilité civile délictuelle et contractuelle, conventions de responsabilité, clause pénale, assurances de responsabilité, fonds de garantie. 6a ed. París: Montchrestien, 1983.

Mirow, Matthew. "The power of codification in Latin America. Simón Bolívar and the Code Napoleon". Tulane Journal of International and Comparative Law 8 (2000): 83-116, https://ecollections.law.fiu.edu/cgi/viewcontent.cgi?referer $=\&$ thtpsredir=1 \&article $=1120$ \&context=faculty_publications (acceso septiembre 21, 2021).

Navas Camargo, Fernanda. "El Sur Global y la realidad social de América Latina: hacia la construcción de nuevos paradigmas". Novum Jus 14, núm. 2 (2020): 11-21. https:// novumjus.ucatolica.edu.co/article/view/3689 (acceso septiembre 21, 2021).

Ospina Fernández, Guillermo y Eduardo Ospina Acosta. Teoría general del contrato y del negocio jurídico. 7a ed. Bogotá: Temis, 2009.

Palomares García, Nattaly y Jorge Calonje Londoño. "Tratados de libre comercio Colombia-Asia: cuestión preliminar y perfiles de negociación”. Iusta 43, núm. 1 (2015): 17-41, DOI: https://doi.org/10.15332/s1900-0448.2015.0043.06 (acceso septiembre 21, 2021).

Pardo Posada, Nohora Elena. "Un recorrido por los derechos colectivos en la jurisprudencia argentina". Via Inveniendi et Iudicandi 9, núm. 1 (2014): 32-49, DOI: https://doi. org/10.15332/s1909-0528.2014.0001.02 (acceso septiembre 21, 2021).

Pascal, Ancel. "Critères et sanctions de l'abus de droit en matière contractuelle". Cahiers de droit de l'entreprise, núm. 6 (1998): 31-46.

Patarroyo Rengifo, Santiago y Paola Andrea Benavides Gómez. "Rupturas asignificantes: revisiones críticas en torno al derecho". Via Inveniendi et Iudicandi 9, núm. 1 (2014): 7-31, DOI: https://doi.org/10.15332/s1909-0528.2014.0001.01 (acceso septiembre 21, 2021).

Perreau, Etienne. "Origines et développement de la théorie de l'abus du droit". Revue générale du droit (1913): 481-507.

Pothier, Robert Joseph. Traité des obligations, selon les regles tant du for de la conscience, que du for extérieur. París: Debure l'aîné, 1764.

Pothier, Robert Joseph. Traité du contrat de louage. Tomo IV. París: Debure Père, 1848. 
Quiroz Villalobos, Milton. “Acercamiento a las 'oposiciones paradigmáticas' entre neoconstitucionalismo y positivismo jurídico". Iusta 2, núm. 41 (2015): 77-97, DOI: https:// doi.org/10.15332/s1900-0448.2014.0041.03 (acceso septiembre 21, 2021).

Ramos Núñez, Carlos Augusto. El Código napoleónico y su recepción en América Latina. Lima: Pontificia Universidad Católica del Perú, 1997.

Real Academia Española. "Abusar" en Diccionario de la lengua española. https://dle.rae.es/ abusar (acceso septiembre 21, 2021).

Rengifo García, Ernesto. Del abuso del derecho al abuso de la posición dominante. Bogotá: Universidad Externado de Colombia, 2004.

Ripert, Georges y Jean Boulanger. Traité de droit civil: d'après le traité de Planiol. Tomo II. París: LGDJ, 1957.

Ripert, Georges. "Abus ou relativité des droits". Revue Critique de Legislation et de Jurisprudence 33, núm. 1 (1929): 3-21, https://heinonline.org/HOL/LandingPage?handle=hein. journals/rcritlgj88\&div=4\&id=\&page $=($ acceso septiembre 21, 2021).

Ripert, Georges. La règle morale dans les obligations civiles. París: LGDJ, 1949.

Rodríguez Martínez, Eduardo. "El pasaje del Estado y el derecho a la postmodernidad". Via Inveniendi et Iudicandi 11, núm. 2 (2016): 11-37, https://doi.org/10.15332/ s1909-0528.2016.0002.01 (acceso septiembre 21, 2021).

Sänger, Rafael. "La garantía de la propiedad y el principio de proporcionalidad como límites de la carga tributaria en Alemania". Iusta, núm. 42 (2015); 73-99, https:// revistas.usantotomas.edu.co/index.php/iusta/article/download/2480/2416 (acceso septiembre 21, 2021).

Stijns, Sophie. "Abus, mais de quel(s) droit(s)? - Réflexions sur l'exécution de bonne foi des contrats et l'abus de droits contractuels". Journal des Tribunaux (1990): 33.

Stoffel-Munck, Philippe. L'abus dans le contrat: essai d'une théorie. París: LGDJ 2000.

Terré, François, Philippe Simler e Yves Lequette. Droit civil: les obligations. París: Dalloz, 2011.

Torrejano Vargas, Rodrigo Hernán y Henry Bocanegra Acosta. "Con el futuro que soñamos los neogranadinos: proposiciones de avance económico para una nueva realidad social (1778-1813)". Via Inveniendi et Iudicandi 16, núm. 2 (2021). DOI: https://doi. org/10.15332/19090528.6784 (acceso septiembre 21, 2021).

Villey, Michel. "La genèse du droit subjectif chez Guillaume d'Occam". Archives de philosophie du droit (1964): 97-127.

Villey, Michel. Le droit et les droits de l'homme. París: PUF, 1990.

Villey, Michel. Philosophie du droit. 4a ed. Tomo I. París: Dalloz, 1986. 